九州大学学術情報リポジトリ

Kyushu University Institutional Repository

アトピー性皮膚炎などの慢性湿疹に対する、芳香族 炭化水素受容体（AHR）の内因性リガンドである6formyl indolo3，2-b-carbazole (FICZ) の治療的効 果について

小田，真理

http://hdl. hand le. net/2324/1959086

出版情報：Kyushu University，2018，博士（医学），課程博士 バージョン：

権利関係 : ๑ 2018 Japanese Society for Investigative Dermatology. Published by Elsevier B.V. All rights reserved. 


\title{
Protective role of 6-formylindolo[3,2-b]carbazole (FICZ), an endogenous ligand for arylhydrocarbon receptor, in chronic mite-induced dermatitis
}

\author{
Mari Kiyomatsu-Oda ${ }^{a, *}$, Hiroshi Uchi ${ }^{a}$, Saori Morino-Koga ${ }^{c}$, Masutaka Furue ${ }^{a, b}$ \\ a Department of Dermatology, Graduate School of Medical Sciences, Kyushu University, 3-1-1 Maidashi, Higashi-ku, Fukuoka 812-8582, Japan \\ ${ }^{\mathrm{b}}$ Research and Clinical Center for Yusho and Dioxin, Kyushu University Hospital, 3-1-1 Maidashi, Higashi-ku, Fukuoka 812-8582, Japan \\ ${ }^{\mathrm{c}}$ Department of Cell Division, Institute of Molecular Embryology and Genetics, Kumamoto University, 2-2-1 Honjo, Chuo-ku, Kumamoto 860-0811, Japan
}

\section{A R T I C L E I N F O}

\section{Article history:}

Received 6 July 2017

Received in revised form 13 February 2018

Accepted 19 February 2018

\section{Keywords:}

FICZ

Aryl hydrocarbon receptor

Filaggrin

Transepidermal water loss

Dermatitis

\begin{abstract}
A B S T R A C T
Background: Chronic eczema such as atopic dermatitis imposes significant socio-econo-psychologic burdens on the affected individuals. In addition to conventional topical treatments, phototherapy is recommended for patients with extensive lesions. Although immunosuppression is believed to explain its primary effectiveness, the underlying mechanisms of phototherapy remain unsolved. Ultraviolet irradiation generates various tryptophan photoproducts including 6-formylindolo[3,2-b]-carbazole (FICZ). FICZ is known to be a potent endogenous agonist for aryl hydrocarbon receptor (AHR); however, the biological role of FICZ in chronic eczema is unknown.

Objective: To investigate the effect of FICZ on chronic eczema such as atopic dermatitis.

Methods: We stimulated HaCaT cells and normal human epidermal keratinocytes (NHEKs) with or without FICZ and then performed quantitative reverse transcriptase polymerase chain reaction, immunofluorescence, and siRNA treatment. We used the atopic dermatitis-like NC/Nga murine model and treated the mice for 2 weeks with either Vaseline ${ }^{\mathbb{R}}$ as a control, FICZ ointment, or betamethasone 17valerate ointment. The dermatitis score, transepidermal water loss, histology, and expression of skin barrier genes and proteins were evaluated.

Results: FICZ significantly upregulated the gene expression of filaggrin in both HaCaT cells and NHEKs in an AHR-dependent manner, but did not affect the gene expression of other barrier-related proteins. In addition, FICZ improved the atopic dermatitis-like skin inflammation, clinical scores, and transepidermal water loss in NC/Nga mice compared with those of control mice. On histology, FICZ significantly reduced the epidermal and dermal thickness as well as the number of mast cells. Topical FICZ also significantly reduced the gene expression of $I l 22$.

Conclusion: These findings highlight the beneficial role of FICZ-AHR and provide a new strategic basis for developing new drugs for chronic eczema.
\end{abstract}

(c) 2018 Japanese Society for Investigative Dermatology. Published by Elsevier B.V. All rights reserved.

\section{Introduction}

The skin is a sensory organ that recognizes physiologic and pathologic chemical stimuli to ensure self-defense and homeostasis. Aryl hydrocarbon receptor (AHR) is a chemical receptor that can bind and be activated by structurally diverse external and internal chemicals including dioxins as well as various phytochemicals and

Abbreviations: FICZ, 6-formylindolo[3,2-b]-carbazole; AHR, aryl hydrocarbon receptor; NHEKs, normal human epidermal keratinocytes; TEWL, transepidermal water loss; FLG, filaggrin; UV, ultraviolet.

* Corresponding author.

E-mail address: mari1019@med.kyushu-u.ac.jp (M. Kiyomatsu-Oda). photo-induced chemicals with a wide range of affinities [1-4]. Upon ligand binding, the ligand-AHR complex translocates from the cytoplasm to the nucleus, binds to its specific DNA recognition site, and then upregulates the transcription of various responsive genes such as CYP1A1, which is a member of a multigene family of xenobiotic-metabolizing enzymes [1,2].

AHR is an evolutionarily-conserved and widely-expressed multifunctional transcription factor that profoundly modulates the functions of the epidermis and immune system [2,4,5]. A recent study by Di Meglio et al. demonstrated a significant enhancement of imiquimod-induced psoriasis-like skin inflammation in Ahr-null mice [6]. Moreover, their investigation stressed the importance of nonhematopoietic cell types such as epidermal cells, rather than hematopoietic cell types, in recapitulating the exaggerated skin 
inflammation under the Ahr-deleted condition [6]. In addition, the activation of AHR by the intraperitoneal injection of 6-formylindolo[3,2-b]-carbazole (FICZ, a ligand for AHR) potently inhibited the imiquimod-induced skin inflammation [6]. FICZ was originally identified as a tryptophan metabolite that forms after exposure to ultraviolet (UV) or visible light in humans $[7,8]$. Because of its highaffinity binding to AHR and its specific induction of CYP1A1, FICZ is now considered as one of the essential endogenous and physiologic ligands for AHR alongside other dietarily-supplied indoles and flavonoids [7-9]. Although sun-exposed skin is one of the major sources of FICZ, the role of FICZ in skin inflammation is not fully understood.

In the present study, we found that 1) FICZ augmented the expression of filaggrin (FLG) in cultured keratinocytes, and 2) the topical application of FICZ reduced the mite antigen-induced dermatitis and transepidermal water loss (TEWL) in NC/Nga mice.

\section{Materials and methods}

\subsection{Reagents and antibodies}

FICZ was purchased from Enzo Life Sciences (Farmingdale, NY) and was dissolved in dimethyl sulfoxide (DMSO; Sigma-Aldrich, St. Louis, MO) to the concentration of $5 \mathrm{mM}$. Anti-AHR rabbit polyclonal IgG antibody (H-211) and normal mouse IgG were obtained from Santa Cruz Biotechnology (Dallas, TX). Anti-FLG (ab3137) antibody was purchased from Abcam (Cambridge, UK).

\subsection{Cell culture}

Human immortalized HaCaT cells were cultured in Dulbecco's modified Eagle's medium containing $10 \%(\mathrm{v} / \mathrm{v})$ fetal bovine serum and antibiotics at $37^{\circ} \mathrm{C}$ in $5 \% \mathrm{CO}_{2}$. HaCaT cells $\left(2 \times 10^{5}\right.$ cells/well $)$ were seeded in 6-well culture plates, allowed to attach for $24 \mathrm{~h}$, and subsequently treated with or without FICZ when they reached $70-90 \%$ confluence.

Normal human epidermal keratinocytes (NHEKs) obtained from Lonza (Walkersville, $\mathrm{MD}$ ) were maintained at $37^{\circ} \mathrm{C}$ in $5 \% \mathrm{CO}_{2}$. The NHEKs were cultured in serum-free keratinocyte growth medium (Lonza) containing bovine pituitary extract, recombinant epidermal growth factor, insulin, hydrocortisone, transferrin, GA1000 , and epinephrine. The culture medium was replaced every 2 days. Third-to-fifth-passage NHEKs were used in all experiments. NHEKs $\left(1 \times 10^{5}\right.$ cells/well) were seeded in 24 -well culture plates, allowed to attach for $24 \mathrm{~h}$, and then treated with or without FICZ when they reached $80-90 \%$ confluence.

\subsection{Immunofluorescence}

HaCaTcells or NHEKs $\left(1 \times 10^{4}\right.$ cells/well $)$ were plated on an 8 -well $\mu$-slide (Ibidi, Munich, Germany) for $48 \mathrm{~h}$, and treated with or without FICZ for 3 or $1 \mathrm{~h}$, respectively. Then, the cells were washed with phosphate-buffered saline(PBS), fixed with acetone for $10 \mathrm{~min}$, and blocked with $5 \%(\mathrm{w} / \mathrm{v})$ bovine serum albumin in PBS for $30 \mathrm{~min}$. The cells were then incubated with primary rabbit anti-AHR antibody (1:100) overnight at $4{ }^{\circ} \mathrm{C}$. Specific binding was detected using a horseradish peroxidase-conjugated goat anti-rabbit antibody followed by tyramide labeling with green-fluorescent Alexa Fluor ${ }^{\circledR} 488$ (Molecular Probes, Eugene, OR) for $1 \mathrm{~h}$ at room temperature in accordance with the manufacturer's instructions. The treated cells were covered with UltraCruz ${ }^{\mathrm{TM}}$ mounting medium containing 4',6-diamidino-2-phenylindole (Santa Cruz Biotechnology). The fluorescence images were analyzed using an EVOS ${ }^{\circledR}$ FL cell imaging system (Life Technologies, Carlsbad, CA).

NHEKs $\left(2.5-4.0 \times 10^{4}\right.$ cells/well) were cultured on an 8-well slide (Lab-Tek, Rochester, NY) with or without FICZ for $24 \mathrm{~h}$. The cells were incubated with primary mouse anti-FLG antibody $(1: 100)$ in WesternBreeze ${ }^{\circledR}$ blocker diluent (Invitrogen, Carlsbad, CA) overnight at $4{ }^{\circ} \mathrm{C}$. Slides were washed in PBS before incubation with an anti-mouse secondary antibody (Alexa Fluor ${ }^{\circledR}$ 546, Life Technologies) for $1 \mathrm{~h}$ at room temperature. All samples were analyzed using a D-Eclipse confocal laser scanning microscope (Nikon, Tokyo, Japan).

\subsection{Real-time quantitative reverse transcriptase polymerase chain reaction ( $q R T-P C R)$}

NHEKs or HaCaT cells were treated with or without FICZ for 3 or $5 \mathrm{~h}$, respectively. Total RNA was extracted using the RNeasy ${ }^{\mathbb{R}}$ Mini kit (Qiagen, Hilden, Germany). The dorsal skin of NC/Nga mice affected by mite-induced dermatitis was treated with each ointment for 2 weeks, and then total RNA was extracted using the RNeasy ${ }^{\mathbb{R}}$ fibrous tissue mini kit (Qiagen). qRT-PCR was performed with PrimeScript ${ }^{\mathrm{TM}}$ RT-reagent and SYBR ${ }^{\circledR}$ Premix Ex Taq ${ }^{\mathrm{TM}} \mathrm{II}$ (Takara Bio, Ōtsu, Japan) according to the manufacturer's instructions. qRT-PCR amplifications were performed with the following cycling conditions: $95^{\circ} \mathrm{C}$ for $30 \mathrm{~s}$, then 40 cycles at $95^{\circ} \mathrm{C}$ for $5 \mathrm{~s}$ (denaturation) and $60^{\circ} \mathrm{C}$ for $20 \mathrm{~s}$ (annealing/extension). The mRNA level of each target gene was normalized to the cycle threshold of $\beta$-actin $(A C T B$; internal control). The primer sequences are listed in Table 1.

\subsection{Transfection with siRNA against AHR}

Anti-AHR siRNA (s1200) and control siRNA (negative control \#1) were purchased from Ambion (Austin, TX). NHEKs and HaCaT cells were transfected with siRNA using the Lipofectamine ${ }^{\circledR}$ RNAiMAX transfection reagent in accordance with the manufacturer's protocol. The efficiency of siRNA transfection for downregulating $A H R$ expression was $93.507 \pm 0.308 \%$ as assessed by measuring $A H R$ expression in NHEKs.

\subsection{D-cultured NHEKs as human skin equivalent model}

The human epidermal three-dimensionally (3D) model (EpiDem EPI-200: MatTek, Ashland, MA, USA) was incubated with or without FICZ $(1 \mu \mathrm{M})$ for $72 \mathrm{~h}$ at $37^{\circ} \mathrm{C}$.

Table 1

Primers for real-time quantitative RT-PCR.

\begin{tabular}{lll}
\hline $\begin{array}{l}\text { Gene } \\
\text { (human })\end{array}$ & Primer sequence $\left(5^{\prime}-3^{\prime}\right)$ & \\
\cline { 2 - 3 } & Sense & Antisense \\
\hline CYP1A1 & TAGACACTGATCTGGCTGCAG & GGGAAGGCTCCATCAGCATC \\
FLG & TGAAGCCTATGACACCACTGA & TCCCCTACGCTTTCTTTCCT \\
LCE1A & CCTGCAAGAGTGGCTGAGATG & GGCAGCAGATAGGTTTGTGG \\
LCE1B & TCTGGAGGCTGCTGCTAAAGTG & GGCCTCTGAACTCCAAGACAGAA \\
LCE3D & TTGATGCATGAGTCCCAGATAC & TGACATCCTGGACATCAGACA \\
LCE3E & TCCAGATCCTGATGCTGAGACAA & AGCTCAGCCTGTGAAAGTCAGAA \\
KRT1 & AGAGTGGACCAACTGAAGAGT & ATTCTCTGCATTTGTCCGCTT \\
KRT10 & ATGTCTGTTCGATACAGCTCAAG & CTCCACCAAGGGAGCCTTTG \\
S100A7 & AATTACCTCGCCGATGTCTTTGA & ATGGCTCTGCTTGTGGTAGTC \\
S100A13 & CCTGAGGCTCCAGCTCACTCTA & GTCAGTGGTTCTGCTGCCATTA \\
S100A15 & CTTCAATCCATCGCTACAGTCC & TGCCAATTGGACGGAATATTATCAG \\
CRNN & ATGCCTCAGTTACTGCAAAACA & TCACATCGGCAAACTCTTGCT \\
RPTN & ATGGGGACTGTGCCTTACTAT & TCTCGGTCTTGATCTAAGAGGTT \\
TCHH & CGGAGACCACATGACCCTAAG & AATCGACACGCCCATTACTGT \\
TCHHL1 & AGACAGGTGACTAAACCAGAGAA & TCTTGAGTTGGTGAAGTCCCA \\
HRNR & TCGAGACCATAACAAGAAAGTGG & GTGAGTGTCATCTCTCAGCTTTG \\
SPRR1B & CATTCTGTCTCCCCAAAAA & ATGGGGGTATAAGGGAGTTG \\
SPRR2D & TCTGTGACAGCAAAAGATTC & ATTCAGGGAGTGAAAGATAAA \\
SPRR2E & ATTGGCTCACCTTGTTCCAC & TGGGAACTGACACTGCTGAG \\
SPRR2G & TCCACCATGCCAGGATAAAT & GCTGAAGGGAAGATGATGGA \\
IVL & TCCTCCAGTCAATACCCATCAG & CAGCAGTCATGTGCTTTTCCT \\
$\beta$-actin & ATTGCCGACAGGATGCAGA & GAGTACTTGCGCTCAGGAGGA \\
G6PD & CTACAGGTTCAGATGATGTC & CAGCTTCTCCTTCTCCATTG \\
\hline & & \\
\hline
\end{tabular}




\subsection{Western blotting}

Protein lysates were isolated from cells with lysis buffer (25 mM HEPES, $10 \mathrm{mM} \mathrm{Na} \mathrm{N}_{2} \mathrm{O}_{7} / 10 \mathrm{H}_{2} \mathrm{O}, 100 \mathrm{mM} \mathrm{NaF}, 5 \mathrm{mM}$ EDTA, $2 \mathrm{mM} \mathrm{Na}_{3} \mathrm{VO}_{4}$, and $1 \%$ Triton $\left.^{\mathrm{TM}} \mathrm{X}-100\right)$. The protein concentration was measured using a BCA Protein Assay Kit (Thermo Fisher Scientific, Rockford, IL, USA). Equal amounts of protein $(30 \mu \mathrm{g})$ were dissolved in sample buffer (Nacalai Tesque, Inc., Kyoto, Japan). The lysates were then boiled at $70{ }^{\circ} \mathrm{C}$ for $10 \mathrm{~min}$ and analyzed by NuPAGE ${ }^{\circledR} 4-12 \%$ Bis-Tris gels (Invitrogen, Carlsbad, CA, USA) at $200 \mathrm{~V}$ for $60 \mathrm{~min}$. The proteins were transferred to polyvinylidene difluoride membranes (Millipore, Bedford, MA), which were then probed with the anti-FLG mouse antibody (Santa Cruz Biotechnology, Dallas, TX, USA) and an anti- $\beta$-actin rabbit polyclonal antibody (Cell Signaling Technology, Danvers, MA, USA) overnight at $4{ }^{\circ} \mathrm{C}$. Immunological bands were identified with HRP-conjugated secondary antibodies (Cell Signaling) followed by visualization with SuperSignal ${ }^{\circledR}$ West Pico Chemiluminescence Substrate (Thermo Scientific) using a ChemiDoc touch imaging system (Bio-Rad, Hercules, CA, USA).

\subsection{Mice}

Female NC/Nga mice were purchased from Charles River Laboratory Japan (Yokohama, Japan). They were maintained on a 12-h light/dark cycle under specific pathogen-free conditions. All mice were 9-10 weeks of age. The animal experiments in this study were approved by the Animal Care and Use Committee of Kyushu University School of Medicine.

\subsection{Induction of dermatitis}

Mice were anesthetized with sevoflurane and their hair on the upper back was shaved with a clipper and a shaver. The shaved dorsal and ear skin were treated with $150 \mu \mathrm{L}$ of $4 \%$ sodium dodecyl sulfate (SDS) and 2 or $3 \mathrm{~h}$ later, $100 \mathrm{mg}$ of mite antigen ointment containing Dermatophagoides farinae extract (Biostir Inc. Osaka, Japan) was topically applied to the barrier-disrupted skin. These procedures were repeated twice a week for 3 weeks [10]. Then, the mice were divided into three groups: Group A, ointment base (Vaseline ${ }^{\circledR}$ control) (100 mg/affected area, $n=11$ ); Group B, FICZ ointment ( $100 \mathrm{mg} /$ affected area, $n=11)$; and Group C, betamethasone 17-valerate ointment (100 mg/affected area, $n=12$ ). In addition to continuing the application of $4 \%$ SDS and mite antigen twice per week, each group of mice was topically treated with the respective ointment three times per week for 2 weeks. On day 35 after the initial application of mite antigen, these mice were sacrificed.

\subsection{Evaluation of skin lesions}

The clinical severity of dermatitis was evaluated at weeks 3, 4, and 5. The development of 1) erythema/hemorrhage, 2) scaling/ dryness, 3) edema, and 4) excoriation/erosion was scored as 0 (none), 1 (mild), 2 (moderate), or 3 (severe). The sum of the individual scores was taken as the dermatitis score.

\subsection{Transepidermal water loss}

Transepidermal water loss (TEWL) was measured on the lesional skin using a Vapo Scan AS-VT100RS machine (Asahi Biomed, Tokyo, Japan). Measurement of TEWL was performed at room temperature $\left(23-26^{\circ} \mathrm{C}\right)$ and room humidity (40-55\%). All data are presented as the median of three repeated recordings.

\subsection{Histological observation of the skin}

Portions of the dorsal skin were fixed with $10 \%$ neutral formalin, embedded in paraffin, and sectioned at $3 \mu \mathrm{m}$. Sections were stained with hematoxylin-eosin or toluidine blue.

\subsection{Immunohistochemistry}

Frozen sections ( $5 \mu \mathrm{m}$ ) were immersed in $3 \% \mathrm{H}_{2} \mathrm{O}_{2}$ in methanol to block endogenous peroxidase activity and incubated with a polyclonal anti-mouse FLG antibody (PRB417P; Covance, Princeton, $\mathrm{NJ}$ ) at the dilution of $1: 1000$ for $1 \mathrm{~h}$ at room temperature. The sections were incubated with a secondary antibody, N-Histofine ${ }^{\circledR}$ Simple Stain MAX-PO MULTI (Nichirei Biosciences, Tokyo, Japan) for $30 \mathrm{~min}$ at room temperature. Immunodetection was conducted with 3,3'-diaminobenzidine as a chromogen, followed by light counterstaining with hematoxylin.

\subsection{Statistical analysis}

All data are expressed as mean \pm standard error. Unpaired Student's $t$-test or one-way analysis of variance was used to analyze the results. A p-value of less than 0.05 was considered to indicate a statistically significant difference.

\section{Results}

\subsection{FICZ did not affect the viability of keratinocytes}

Graded concentrations of FICZ $(0-100 \mathrm{nM})$ did not affect the viability of HaCaT cells and NHEKs as determined by the CCK-8 assay (Supplementary Fig. S1).

\subsection{FICZ induced the nuclear translocation of AHR and the upregulation of CYP1A1 expression}

It is known that cytoplasmic AHR translocates to the nucleus and upregulates CYP1A1 expression after binding to various chemicals such as dioxins, flavonoids, and tryptophan photoproducts $[3,4]$. To confirm the nuclear translocation of AHR and the transcriptional activation of CYP1A1 after FICZ treatment, we treated HaCaT cells or NHEKs with DMSO (negative control) or FICZ $(100 \mathrm{nM})$. As expected, in the steady state, AHR was localized mainly in the cytoplasm (Fig. 1A and C), whereas FICZ induced its nuclear translocation (Fig. 1B and D) in concert with a significant upregulation of CYP1A1 expression (Fig. $1 \mathrm{E}$ and $\mathrm{F}$ ). These results indicate the capacity of FICZ to activate AHR signaling.

\subsection{FICZ upregulated FLG expression in an AHR-dependent manner}

Since some AHR ligands such as coal tar and soybean tar are known to upregulate the expression of FLG and other epidermal barrier proteins $[3,4,11,12]$, we next examined the effects of FICZ on the expression of barrier proteins. Although FICZ did not upregulate the expression of LCE1A, LCE1B, LCE3D, LCE3E, KRT1, KRT10, S100A7, S100A13, S100A15, CRNN, RPTN, TCHH, TCHHL1, HRNR, SPRR1B, SPRR2E, SPRR2G, and IVL (Supplementary Fig. S2), a significant upregulation of $F L G$ and $S P R R 2 D$ expression was observed. Since it is well known that FLG is important to maintain the epidermal barrier, we decided to focus on FLG expression. FICZ upregulated the expression of the CYP1A1 (Fig. 2A) and FLG (Fig. 2B) in a dose-dependent manner in HaCaT cells. NHEKs were more sensitive than HaCaT cells in their response to FICZ and concentrations of FICZ as low as $1 \mathrm{nM}$ induced a significant upregulation of CYP1A1 (Fig. 2C) and FLG (Fig. 2D) expression. 


\section{$\mathrm{HaCaT}$ cells}

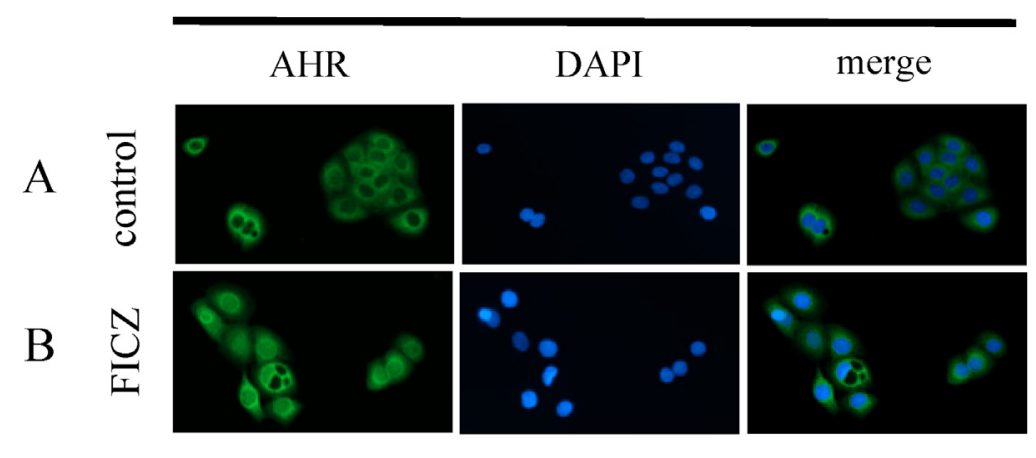

NHEKs

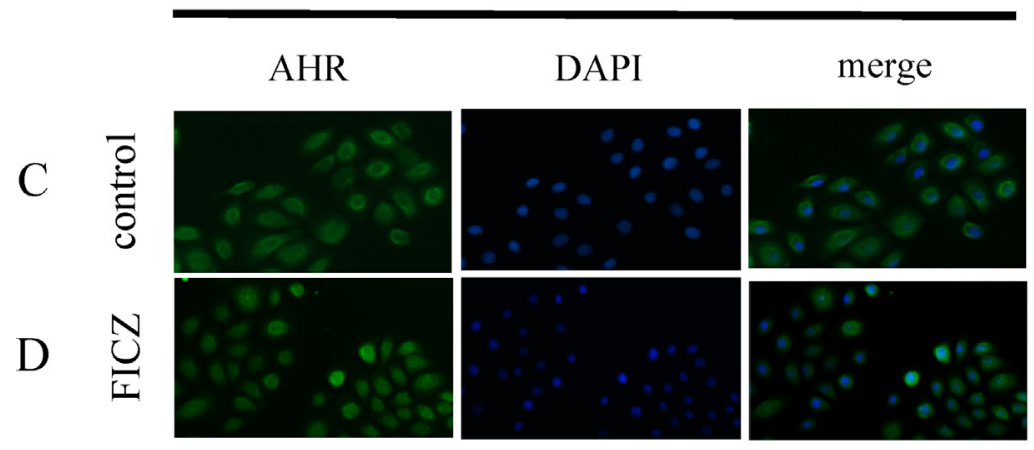

E

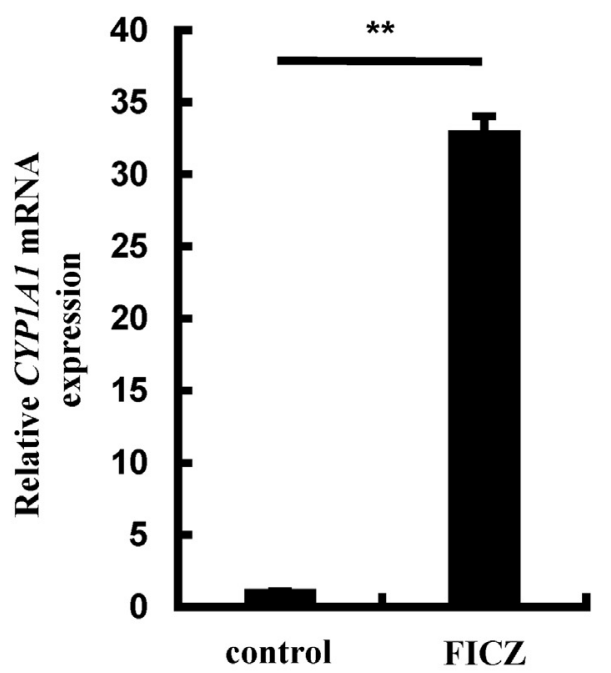

F

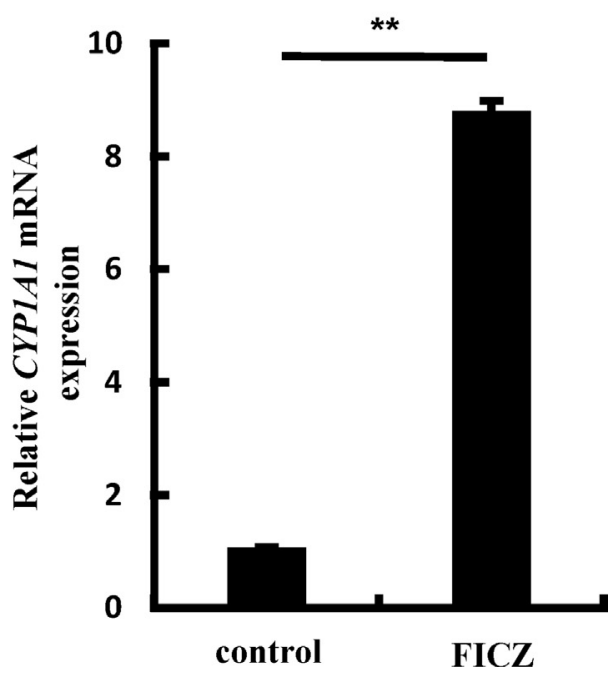

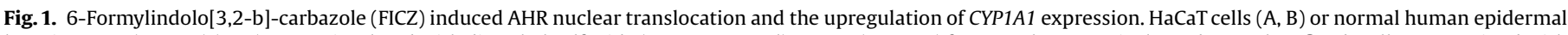

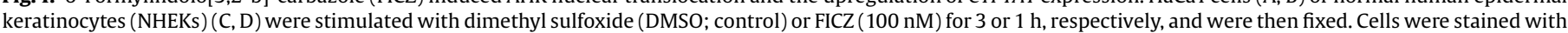

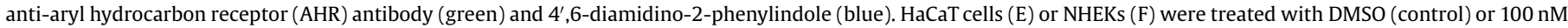

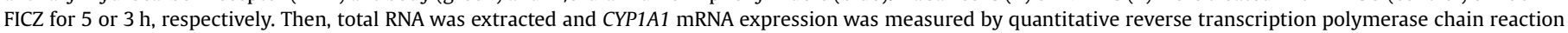

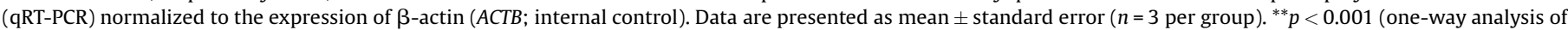
variance).

\subsection{FICZ increased the abundance of filaggrin (FLG) protein}

We further investigated the abundance of FLG protein. The keratinocytes or 3D cultured NHEKs were treated with DMSO (negative control) or FICZ for $24 \mathrm{~h}$ to $96 \mathrm{~h}$, and then the abundance of FLG was examined by immunolabeling and fluorescence microscopy or western blotting. As expected, the abundance of FLG or Pro-FLG was augmented in the FICZ-treated keratinocytes 
A

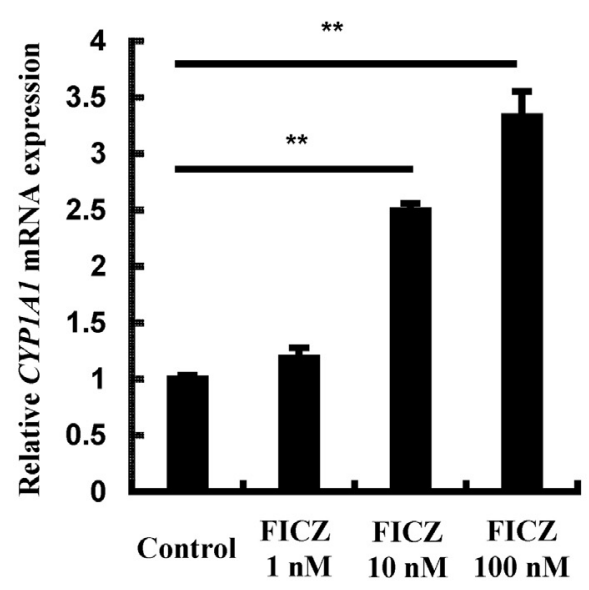

$\mathrm{C}$

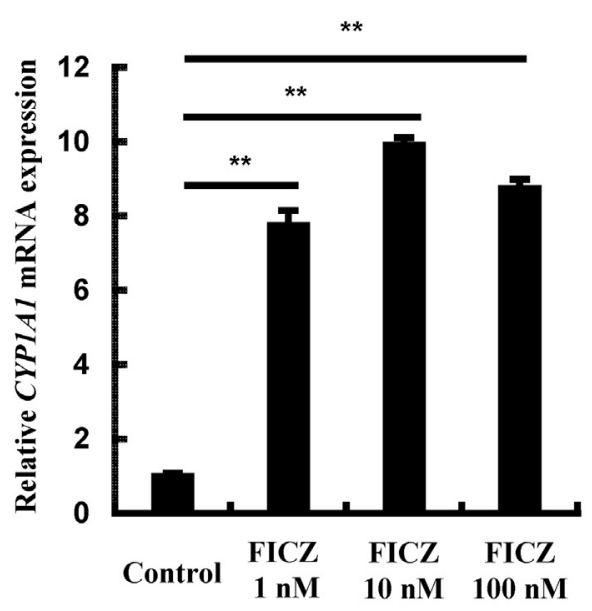

B

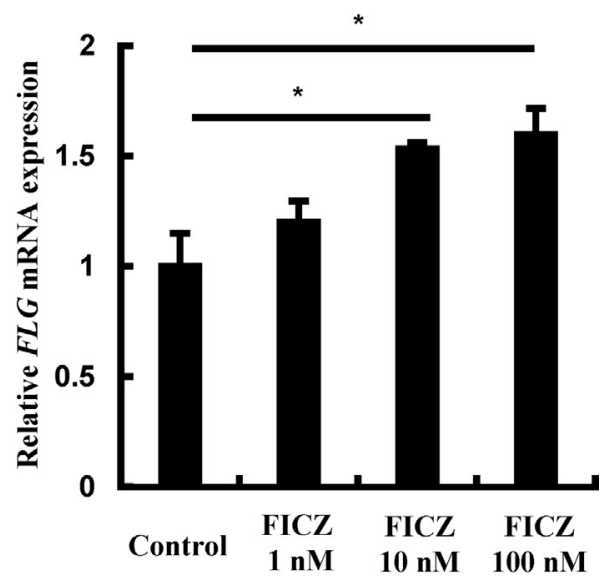

$\mathrm{D}$

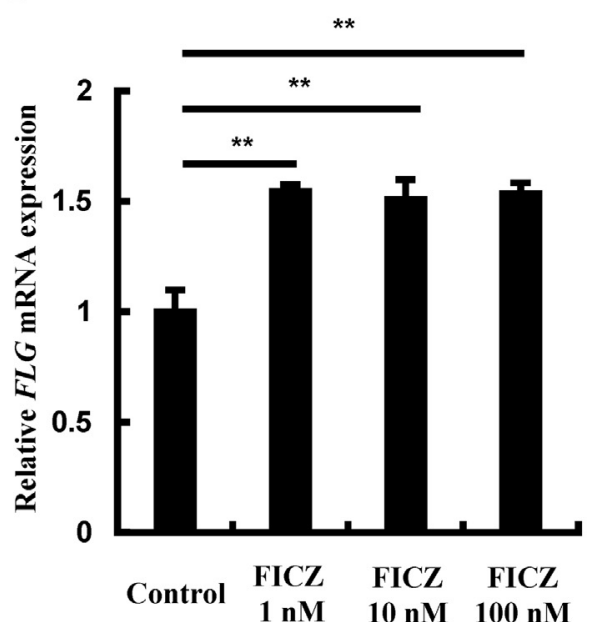

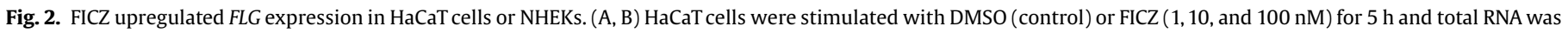

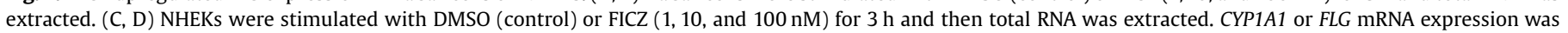

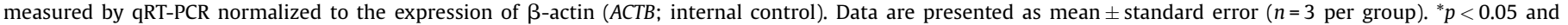
${ }^{* *} p<0.001$ (one-way analysis of variance).

or 3D cultured NHEKs compared to that in their untreated counterparts (Fig. 3 and Supplementary Fig. S6).

\subsection{AHR-dependency of the response to FICZ}

We assessed the AHR-dependency of the induction of FLG expression by FICZ using AHR-knockdown keratinocytes transfected with anti-AHR siRNA. As expected, the enhancing effect of FICZ on FLG expression was completely abrogated both in HaCaT cells (Fig. 4A) and NHEKs (Fig. 4B) transfected with anti-AHR siRNA. These results indicate that the FICZ-induced upregulation of FLG is AHR-dependent.

\subsection{FICZ improved mite-induced chronic dermatitis and TEWL in NC/ Nga mice}

Since the expression of FLG is essentially involved in human atopic dermatitis and murine experimental dermatitis models [1316] as well as physiological epidermal barrier recovery [17], we next investigated whether the topical application of FICZ could improve mite-induced chronic dermatitis in vivo. The NC/Nga mice were epicutaneously treated with mite antigen and SDS twice per week for 5 weeks (Supplementary Fig. S3). This procedure induced a visible, stable, and chronic dermatitis at 3, 4, and 5 weeks after the initial application of mite antigen.

From week 3 , these mice with dermatitis were topically treated with Vaseline ${ }^{\circledR}$ as a control, FICZ ointment, and a commercially available betamethasone 17 -valerate ointment. Vaseline ${ }^{\circledR}$ treatment could not improve the ongoing dermatitis, while both topical FICZ and betamethasone improved the dermatitis (Fig. 5A). After 2 weeks of application (at week 5), a significant improvement was observed only in the group treated with topical FICZ (Fig. 5B). Consistent with the beneficial effect on the dermatitis score, TEWL was also improved by FICZ and betamethasone, and a significant improvement of TEWL was detected only in the group treated with topical FICZ after 2 weeks of application (Fig. 5C).

\subsection{FICZ restored FLG expression and improved skin inflammation}

The mite-induced dermatitis in NC/Nga mice induces a downregulation of FLG expression alongside an increase in skin thickness and augmented mast cell infiltration [18]. The expression of FLG in normal mice was detected mainly along the thin granular layer (Fig. 6A), but it was reduced in the dermatitis-affected skin in 


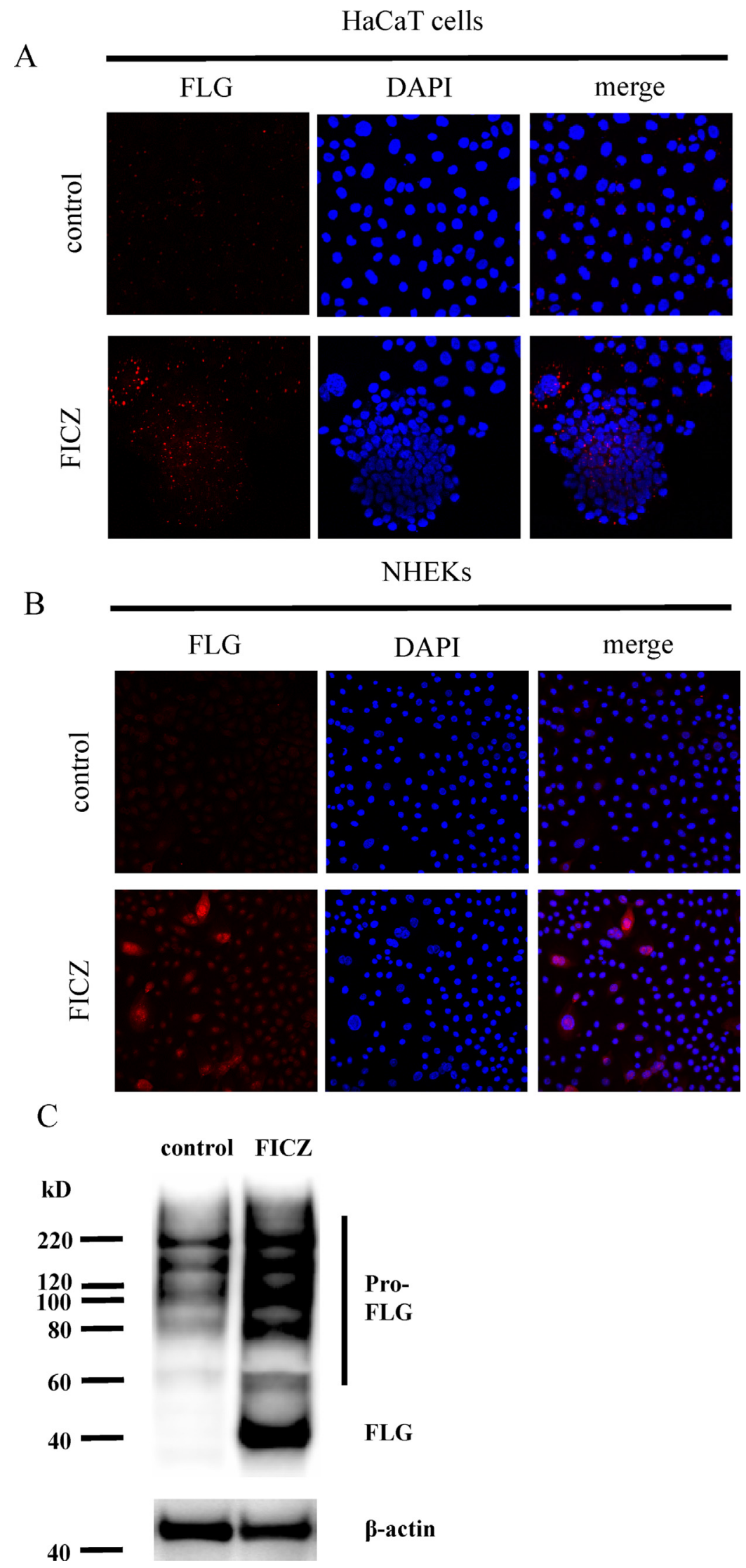

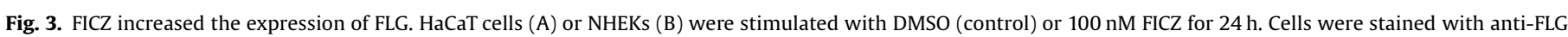
antibody (green) and 4',6-diamidino-2-phenylindole (blue). 3D-cultured NHEKs (C) were treated with DMSO (control) or FICZ (1 $\mu$ M) for $72 \mathrm{~h}$. Total cell lysates were prepared and analyzed with an anti-FLG antibody by western blotting. Data are representative of experiments repeated three times with similar results. 
A

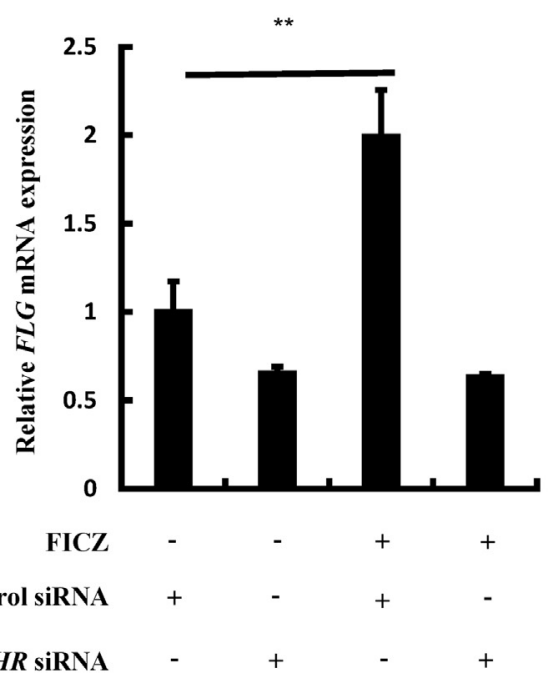

B

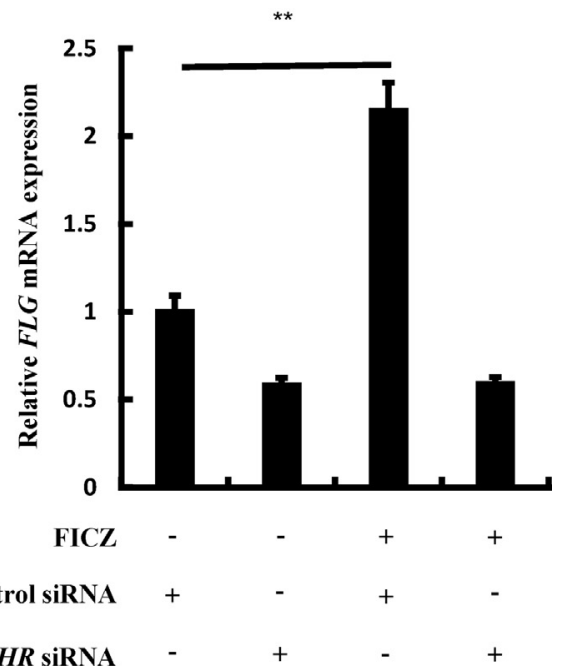

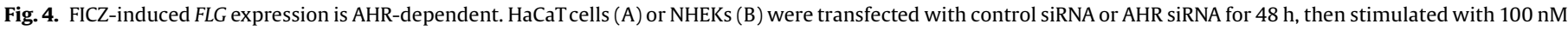

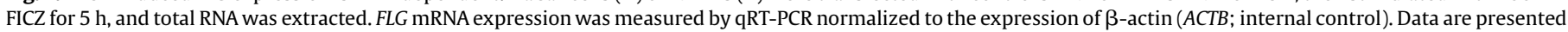
as mean \pm standard error ( $n=3$ per group). ${ }^{* *} p<0.001$ (one-way analysis of variance).

the Vaseline ${ }^{\circledR}$ control group (Fig. 6B). However, topical FICZ recovered the expression of FLG in the dermatitis-affected skin (Fig. 6C). Topical betamethasone also recovered the expression of FLG but to a lesser extent (Fig. 6D). Furthermore, on histology, the thickness of skin (epidermis and dermis) was significantly reduced in the topical FICZ and betamethasone groups compared to that in the Vaseline ${ }^{\circledR}$ control group (Fig. 6E). Both topical FICZ and betamethasone also reduced the number of infiltrated mast cells and $\mathrm{CD}^{+} 8^{+}$cells compared to that in the Vaseline ${ }^{\circledR}$ control group (Supplementary Fig. S4 and S5).

\subsection{FICZ regulated the expression of cytokines including Il22 and Ifng}

Finally, we addressed the cytokine milieu in the dermatitisaffected skin treated with Vaseline ${ }^{\circledR}$, FICZ, and betamethasone by measuring the mRNA expression levels of $I l 1 A, I l 1 B, I l 4, I l 6, I l 13$, Il17A, Il22, Ifng, and Tnfa. Topical FICZ significantly reduced the expression of Il22 and Ifng, but did not affect the expression of the other cytokine genes (Fig. 7). Topical betamethasone inhibited the expression of Ifng only (Fig. 7).

\section{Discussion}

In this study, we demonstrated that FICZ upregulates the expression of FLG in keratinocytes in an AHR-dependent fashion and that the topical application of FICZ potently inhibits the ongoing mite-induced chronic dermatitis in the NC/Nga murine model. In this model, topical FICZ improved the TEWL of the treated dermatitis lesions and maintained a normal expression of FLG.

AHR is a xenobiotic chemical sensor that is abundantly expressed in barrier-forming epithelial tissues such as skin, trachea, and intestine [3,19-23]. Various xenobiotic and natural compounds such as dioxins, dietary polyphenols including flavonoids, and microbiota-derived factors can activate AHR and upregulate CYP1A1 expression leading to the induction of oxidant and/or antioxidant signaling pathways in a ligand-dependent manner [3,5,24]. AHR is also an important regulator of the development and function of both innate and adaptive immune cells and is indispensable for the maturation of intestinal immunity [5,21,22,25,26].

In addition, AHR is an essential transcription factor for human epidermal differentiation complex genes including $F L G$ [4,27-29].
Some medicinal ligands for AHR such as coal tar and soybean tar actively upregulate $F L G$ expression $[11,12]$. The barrier function is significantly disrupted in Ahr-null mice, indicating that AHR plays a pivotal role in skin barrier integrity [23]. Since the tryptophan photoproduct FICZ is a high-affinity endogenous ligand for AHR $[7,8,30]$, we examined the effect of FICZ on the expression of FLG in keratinocytes. The present study confirmed that FLG expression is augmented by FICZ and that the induction of FLG expression by FICZ does not occur in AHR-knockdown keratinocytes.

Previous studies have shown that the systemic injection of FICZ inhibits dextran sulfate sodium-induced colitis [31], ovalbumin-induced allergic asthma [32], and topical imiquimod-induced psoriasis [6] in mice. In parallel with these reports, topical FICZ significantly inhibited mite-induced chronic dermatitis in the present study. The mite-induced dermatitis in NC/Nga mice has been reported to be associated with an enhanced skin thickness, an accumulation of dermal mast cells, an increased TEWL, and a decreased expression of FLG [18]. In addition, a high number of $\mathrm{CD} 68^{+}$macrophages has been detected in the dermis of atopic dermatitis skin lesions [33]. All these features were significantly normalized by the topical application of FICZ in the present study. Although FLG is one of many barrier proteins [29], it is likely to be involved in the functional integrity of the epidermal barrier [14]. A loss-of-function mutation of FLG causes dry skin and is critically involved in the pathogenesis of atopic dermatitis and experimental animal disease phenotypes $[13,15,34]$. Moreover, the topical application of apigenin, a phytochemical AHR activator, improves epidermal barrier homeostasis by upregulating FLG expression in normal murine skin [17]. These studies suggest that the AHR-mediated FLG upregulation by FICZ may be an integral part of the therapeutic modality of FICZ as a potential treatment for dermatitis.

Our analysis of gene expression in the treated dermatitisaffected skin revealed that FICZ significantly downregulated the expression of Il22 and Ifng. Betamethasone treatment significantly inhibited the expression of Ifng, but not that of Il22. Considering the weak and insignificant clinical effect of betamethasone, the inhibitory action of FICZ on Il22 expression may be meaningful in our experimental model. Recent studies have stressed the pathogenetic role of IL-22 in human atopic dermatitis and mite-induced murine dermatitis [35-38]. IL-22 markedly 
A

\section{Start}

(Day 21)

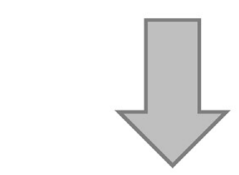

Treated for a week

(Day 28)

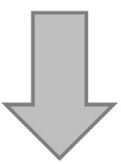

Treated for 2 weeks

(Day 35)
Vaseline
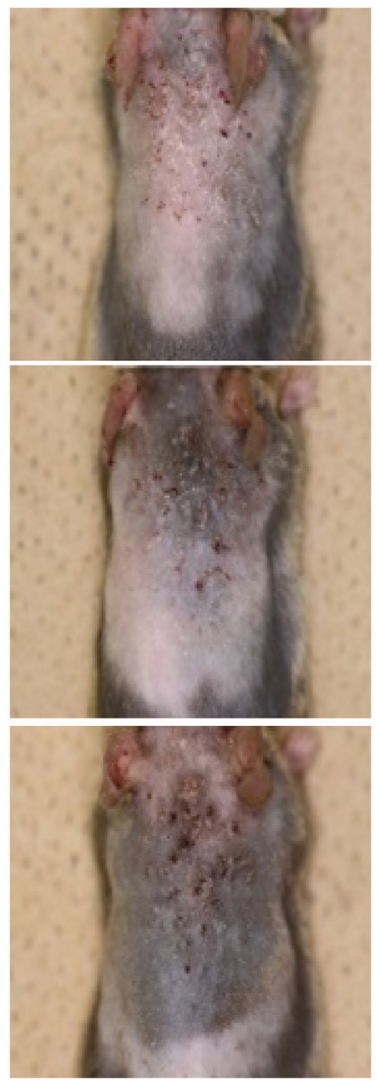

B

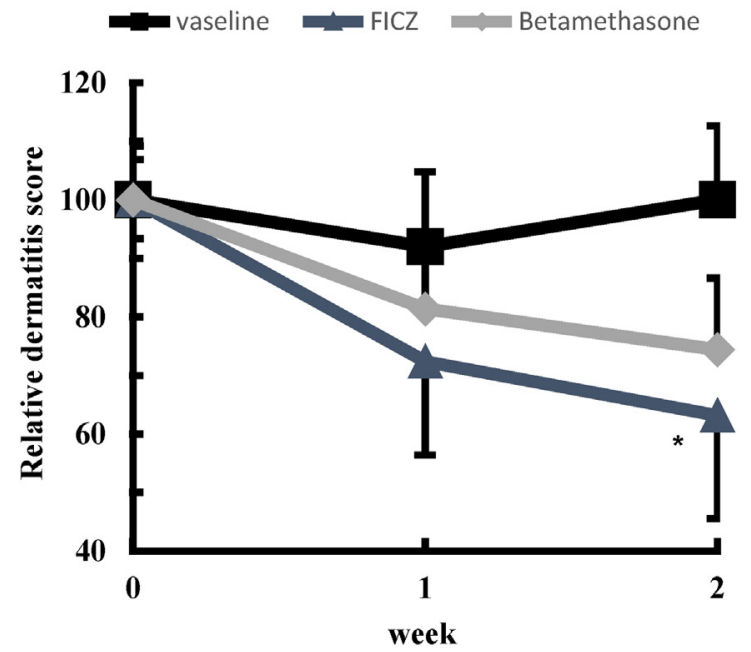

FICZ
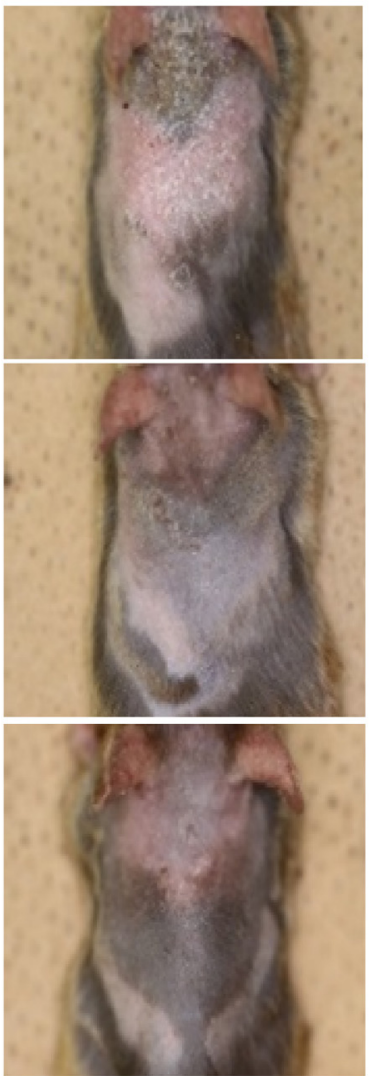

Betamethasone

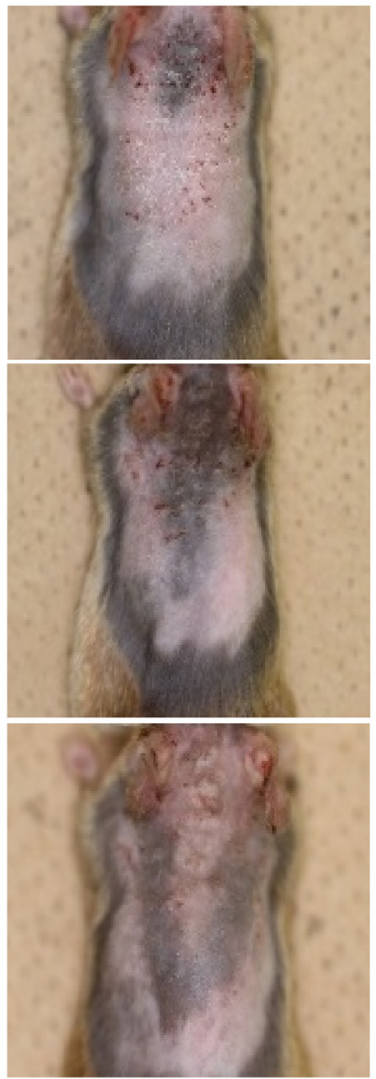

C

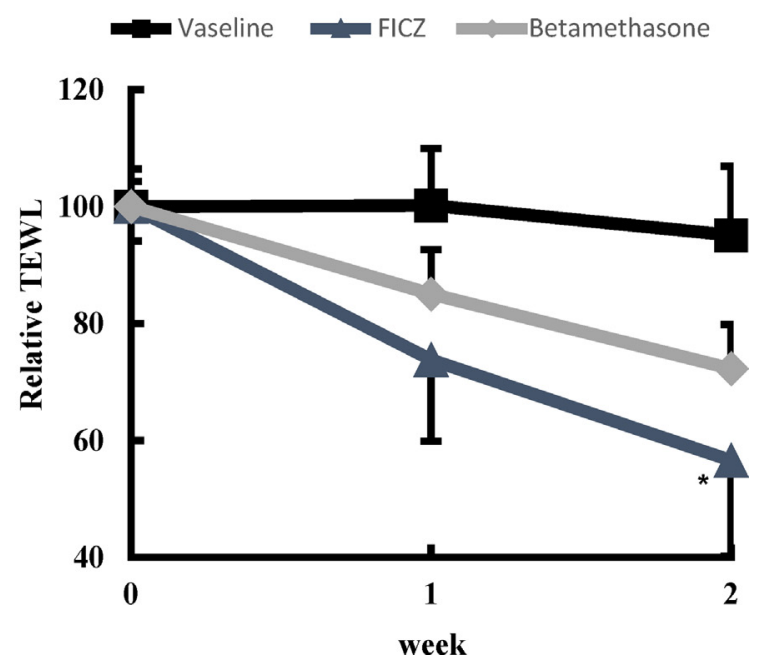

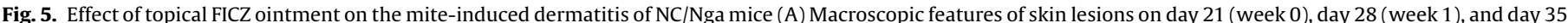

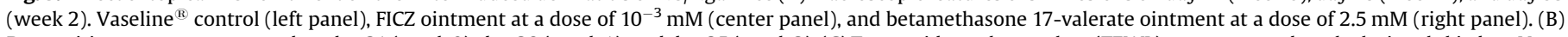

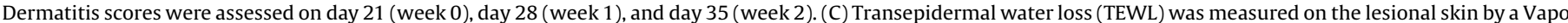

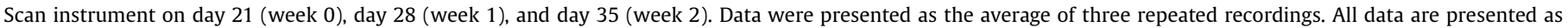
mean \pm standard error ( $n=11-12$ per group). ${ }^{*} p<0.05$ (one-way analysis of variance) compared to the Vaseline ${ }^{\mathbb{R}}$ control group..

downregulates FLG expression [39,40]. Moreover, therapeutic success in atopic dermatitis is associated with the downregulation of IL-22, the enhancement of FLG expression, and the improvement of TEWL [37]. Therefore, the downregulation of Il22 may potentially be related to the effectiveness of FICZ treatment. In accordance with this notion, the FICZ-induced downregulation of $I l 22$ was evident in the imiquimod-induced psoriasis model [6]. However, it is enigmatic that FICZ augments IL-22 production by $\mathrm{T}$ cells and innate lymphoid cells in vitro $[41,42]$. 
A

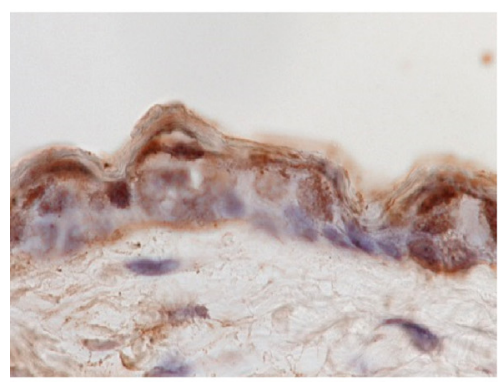

$\mathrm{C}$

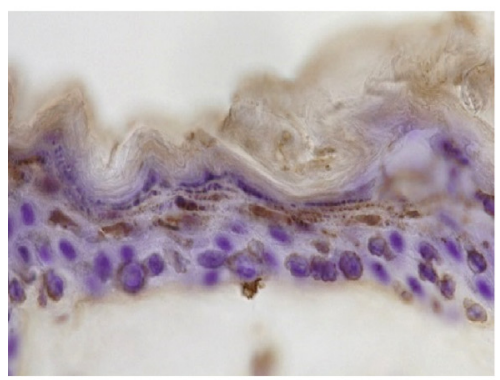

B Vaseline

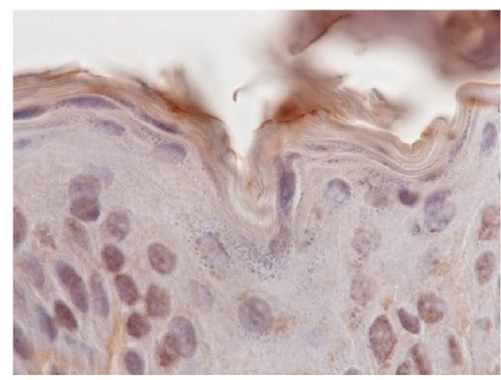

\section{Betamethasone}

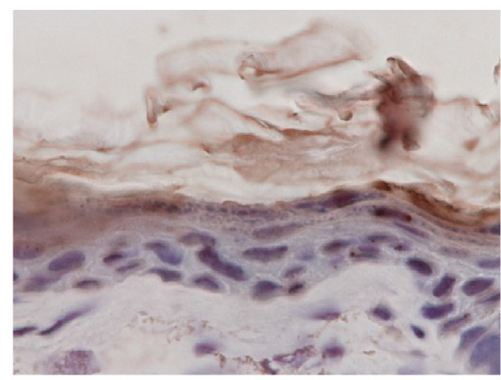

$\mathrm{E}$
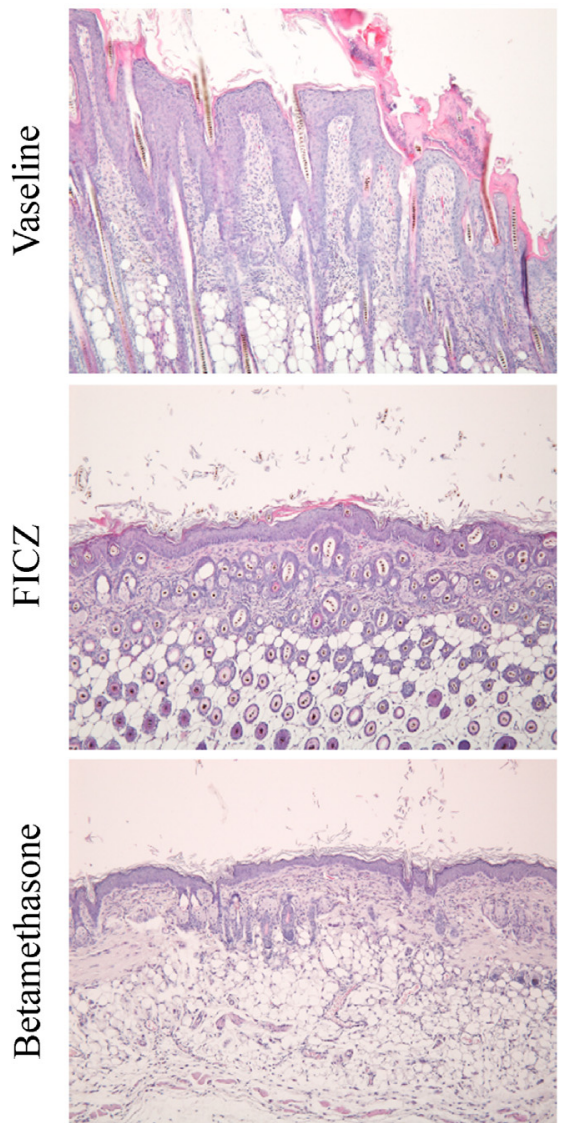

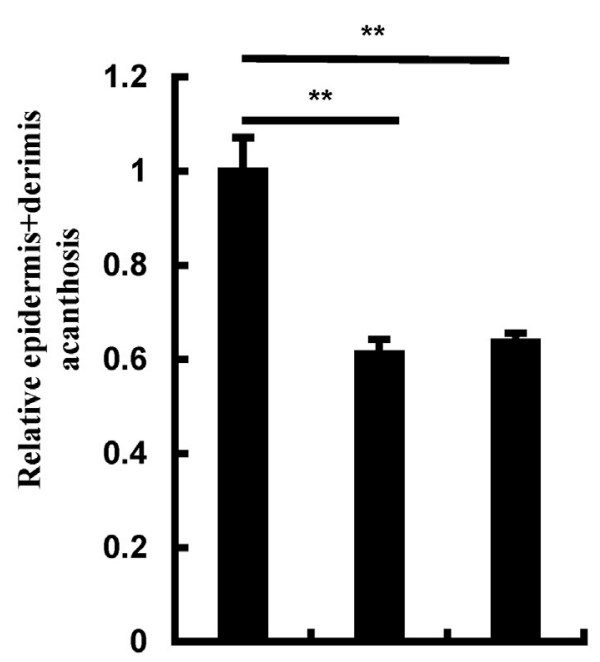

Vaseline FICZ Betamethasone

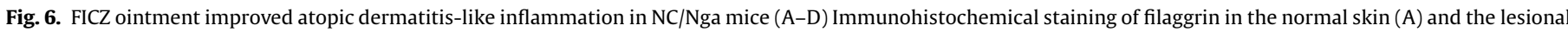

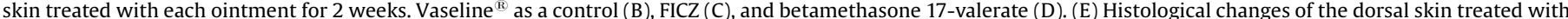

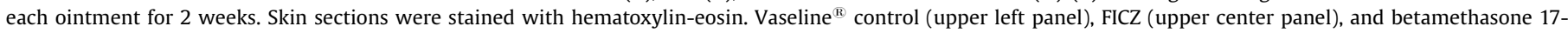

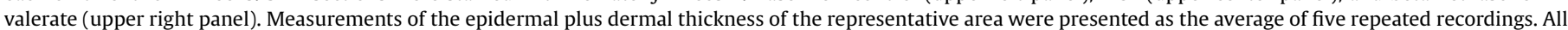
data are presented as mean \pm standard error $\left(n=11-12\right.$ per group). ${ }^{* *} p<0.001$ (one-way analysis of variance) compared to the Vaseline ${ }^{\mathbb{R}}$ control group. 
A

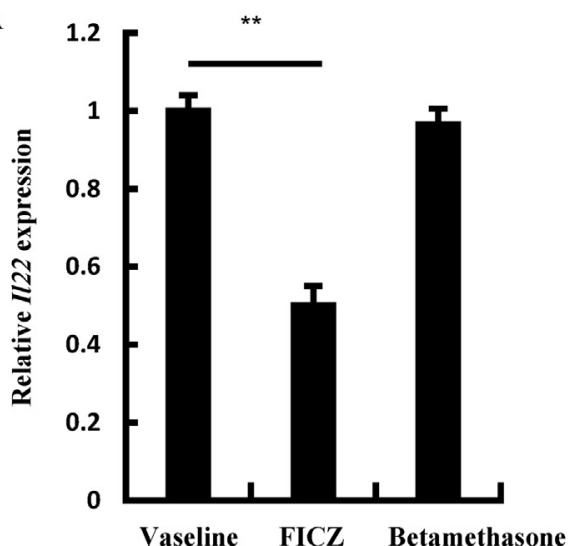

B

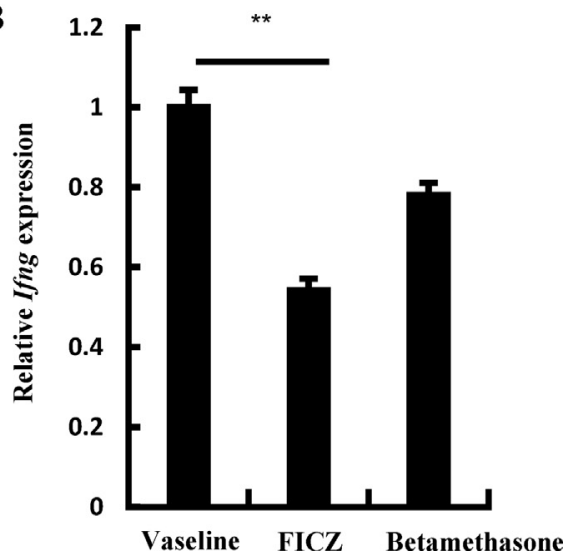

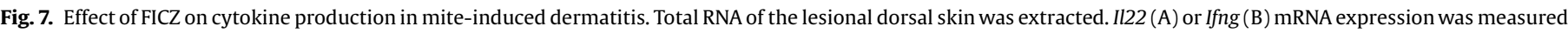

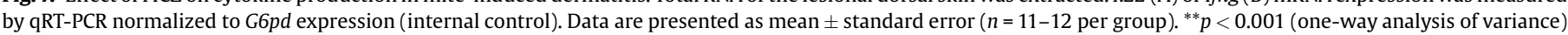
compared to the Vaseline ${ }^{\overline{\mathbb{R}}}$ control group.

Phototherapy is useful for inflammatory skin diseases [43-45]. Suberythematous doses of UV radiation cause immunosuppression [46]. It is known that AHR is involved in this UV-mediated immunosuppression [47]. Moreover, suberythematous doses of UV radiation can upregulate FLG expression and reinforce the function of the epidermal barrier [48]. Since FICZ is the main tryptophan photoproduct generated by UV radiation and is a high-affinity endogenous ligand for AHR [7], the immunosuppressive and barrier-protective effects of UV may be mediated, at least in part, by FICZ.

In conclusion, topical FICZ inhibits the ongoing mite-induced chronic dermatitis in $\mathrm{NC} / \mathrm{Nga}$ mice in concert with upregulating FLG expression via AHR, improving TEWL, and reducing Il22 gene expression in the treated site. The beneficial effects of FICZ may recapitulate the salubrious properties of UV radiation. The development of AHR-targeting drugs may be promising for the treatment of inflammatory skin diseases.

\section{Conflict of interest}

The authors have no conflict of interest to declare.

\section{Acknowledgement}

This work was supported by grants from The Ministry of Health, Labour and Welfare, Japan (grant number: 15K09770).

\section{Appendix A. Supplementary data}

Supplementary data associated with this article can be found, in the online version, at https://doi.org/10.1016/j.jdermsci.2018.02.014.

\section{References}

[1] J. Mimura, Y. Fujii-Kuriyama, Functional role of AhR in the expression of toxic effects by TCDD, Biochim. Biophys. Acta 2003 (1619) 263-268.

[2] N. Hao, M.L. Whitelaw, The emerging roles of AhR in physiology and immunity, Biochem. Pharmacol. 86 (2013) 561-570.

[3] M. Furue, M. Takahara, T. Nakahara, H. Uchi, Role of AhR/ARNT system in skin homeostasis, Arch. Dermatol. Res. 306 (2014) 769-779.

[4] M. Furue, G. Tsuji, C. Mitoma, T. Nakahara, T. Chiba, S. Morino-Koga, H. Uchi, Gene regulation of filaggrin and other skin barrier proteins via aryl hydrocarbon receptor, J. Dermatol. Sci. 80 (2015) 83-88.

[5] B. Stockinger, P. Di Meglio, M. Gialitakis, J.H. Duarte, The aryl hydrocarbon receptor: multitasking in the immune system, Annu. Rev. Immunol. 32 (2014) 403-432.

[6] P. Di Meglio, J.H. Duarte, H. Ahlfors, N.D. Owens, Y. Li, F. Villanova, I. Tosi, K Hirota, F.O. Nestle, U. Mrowietz, M.J. Gilchrist, B. Stockinger, Activation of the aryl hydrocarbon receptor dampens the severity of inflammatory skin conditions, Immunity 40 (2014) 989-1001.
[7] E. Fritsche, C. Schäfer, C. Calles, T. Bernsmann, T. Bernshausen, M. Wurm, U. Hübenthal, J.E. Cline, H. Hajimiragha, P. Schroeder, L.O. Klotz, A. Rannug, P. Fürst, H. Hanenberg. J. Abel, J. Krutmann, Lightening up the UV response by identification of the arylhydrocarbon receptor as a cytoplasmatic target for ultraviolet B radiation, Proc. Natl. Acad. Sci. U. S. A. 104 (2007) 8851-8856.

[8] E. Wincent, N. Amini, S. Luecke, H. Glatt, J. Bergman, C. Crescenzi, A. Rannug, U. Rannug, The suggested physiologic aryl hydrocarbon receptor activator and cytochrome P4501 substrate 6-formylindolo[3,2-b]carbazole is present in humans, J. Biol. Chem. 284 (2009) 2690-2696.

[9] T.D. Hubbard, I.A. Murray, G.H. Perdew, Indole and tryptophan metabolism: endogenous and dietary routes to ah receptor activation, Drug Metab. Dispos. 43 (2015) 1522-1535.

[10] M. Yamamoto, T. Haruna, K. Yasui, H. Takahashi, M. Iduhara, S. Takaki, M. Deguchi, A. Arimura, A novel atopic dermatitis model induced by topical application with dermatophagoides farinae extract in NC/Nga mice, Allergol. Int. 56 (2007) 139-148.

[11] E.H. van den Bogaard, J.G. Bergboer, M. Vonk-Bergers, IM. van VlijmenWillems, S.V. Hato, P.G. van der Valk, J.M. Schröder, I. Joosten, P.L. Zeeuwen, J. Schalkwijk, Coal tar induces AHR-dependent skin barrier repair in atopic dermatitis, J. Clin. Invest. 123 (2013) 917-927.

[12] K. Takei, C. Mitoma, A. Hashimoto-Hachiya, H. Uchi, M. Takahara, G. Tsuji, M. Kido-Nakahara, T. Nakahara, M. Furue, Antioxidant soybean tar Glyteer rescues T-helper-mediated downregulation of filaggrin expression via aryl hydrocarbon receptor, J. Dermatol. 42 (2015) 171-180.

[13] C.N. Palmer, A.D. Irvine, A. Terron-Kwiatkowski, Y. Zhao, H. Liao, S.P. Lee, D.R. Goudie, A. Sandilands, L.E. Campbell, F.J. Smith, G.M. O’Regan, R.M. Watson, J.E. Cecil, S.J. Bale, J.G. Compton, J.J. DiGiovanna, P. Fleckman, S. Lewis-Jones, G. Arseculeratne, A. Sergeant, C.S. Munro, B. El Houate, K. McElreavey, L.B. Halkjaer, H. Bisgaard, S. Mukhopadhyay, W.H. McLean, Common loss-offunction variants of the epidermal barrier protein filaggrin are a major predisposing factor for atopic dermatitis, Nat. Genet. 38 (2006) 441-446.

[14] G. Egawa, K. Kabashima, Multifactorial skin barrier deficiency and atopic dermatitis: essential topics to prevent the atopic march, J. Allergy Clin. Immunol. 138 (2016) 350-358.

[15] H. Kawasaki, K. Nagao, A. Kubo, T. Hata, A. Shimizu, H. Mizuno, T. Yamada, M. Amagai, Altered stratum corneum barrier and enhanced percutaneous immune responses in filaggrin-null mice, J. Allergy Clin. Immunol. 129 (2012) $1538-1546$.

[16] S.P. Saunders, T. Moran, A. Floudas, F. Wurlod, A. Kaszlikowska, M. Salimi, E.M. Quinn, C.J. Oliphant, G. Núñez, R. McManus, E. Hams, A.D. Irvine, A.N. McKenzie, G.S. Ogg, P.G. Fallon, Spontaneous atopic dermatitis is mediated by innate immunity: with the secondary lung inflammation of the atopic march requiring adaptive immunity, J. Allergy Clin. Immunol. 137 (2016) 482-491.

[17] M. Hou, R. Sun, M. Hupe, P.L. Kim, K. Park, D. Crumrine, T.K. Lin, J.L. Santiago, T. M. Mauro, P.M. Elias, M.Q. Man, Topical apigenin improves epidermal permeability barrier homoeostasis in normal murine skin by divergent mechanisms, Exp. Dermatol. 22 (2013) 210-215.

[18] T. Tsuji, S. Okuno, A. Kuroda, J. Hamazaki, T. Chikami, S. Sakurai, Y. Yoshida, R. Banno, T. Fujita, T. Kohno, Therapeutic approach to mite-induced intractable dermatitis using novel immunomodulator FTY720 ointment (fingolimod) in NC/Nga mice, Allergol. Int. 65 (2016) 172-179.

[19] G. Tsuji, M. Takahara, H. Uchi, S. Takeuchi, C. Mitoma, Y. Moroi, M. Furue, An environmental contaminant benzo(a)pyrene, induces oxidative stressmediated interleukin-8 production in human keratinocytes via the aryl hydrocarbon receptor signaling pathway, J. Dermatol. Sci. 62 (2011) 42-49.

[20] T. Chiba, J. Chihara, M. Furue, Role of the arylhydrocarbon receptor (AhR) in the pathology of asthma and COPD, J. Allergy (Cairo) 2012 (2012) 372384.

[21] E.A. Kiss, C. Vonarbourg, S. Kopfmann, E. Hobeika, D. Finke, C. Esser, A. Diefenbach, Natural aryl hydrocarbon receptor ligands control organogenesis of intestinal lymphoid follicles, Science 334 (2011) 1561-1565. 
[22] Y. Li, S. Innocentin, D.R. Withers, N.A. Roberts, A.R. Gallagher, E.F. Grigorieva, C. Wilhelm, M. Veldhoen, Exogenous stimuli maintain intraepithelial lymphocytes via aryl hydrocarbon receptor activation, Cell 147 (2011) 629-640.

[23] K. Haas, H. Weighardt, R. Deenen, K. Köhrer, B. Clausen, S. Zahner, P. Boukamp, W. Bloch, J. Krutmann, C. Esser, Aryl hydrocarbon receptor in keratinocytes is essential for murine skin barrier integrity, J. Invest. Dermatol. 136 (2016) 2260-2269.

[24] M. Furue, H. Uchi, C. Mitoma, A. Hashimoto-Hachiya, T. Chiba, T. Ito, T. Nakahara, G. Tsuji, Antioxidants for healthy skin: the emerging role of aryl hydrocarbon receptors and nuclear factor-erythroid 2-related factor-2, Nutrients 9 (2017) 223.

[25] L. Zhou, AHR function in lymphocytes: emerging concepts, Trends Immunol. 37 (2016) 17-31.

[26] C. Schiering, E. Wincent, A. Metidji, A. Iseppon, Y. Li, A.J. Potocnik, S. Omenetti, C.J. Henderson, C.R. Wolf, D.W. Nebert, B. Stockinger, Feedback control of AHR signalling regulates intestinal immunity, Nature 542 (2017) 242-245.

[27] C.H. Sutter, S. Bodreddigari, C. Campion, R.S. Wible, T.R. Sutter, 2,3,7,8Tetrachlorodibenzo-p-dioxin increases the expression of genes in the human epidermal differentiation complex and accelerates epidermal barrier formation, Toxicol. Sci. 124 (2011) 128-137.

[28] L.H. Kennedy, C.H. Sutter, S. Leon Carrion, Q.T. Tran, S. Bodreddigari, E. Kensicki, R.P. Mohney, T.R. Sutter, 2,3,7,8-Tetrachlorodibenzo-p-dioxin-mediated production of reactive oxygen species is an essential step in the mechanism of action to accelerate human keratinocyte differentiation, Toxicol. Sci. 132 (2013) 235-249.

[29] M. Kypriotou, M. Huber, D. Hohl, The human epidermal differentiation complex: cornified envelope precursors, S100 proteins and the 'fused genes' family, Exp. Dermatol. 21 (2012) 643-649.

[30] L. Bergander, E. Wincent, A. Rannug, M. Foroozesh, W. Alworth, U. Rannug, Metabolic fate of the Ah receptor ligand 6-formylindolo[3,2-b]carbazole, Chem. Biol. Interact. 149 (2004) 151-164.

[31] I. Monteleone, A. Rizzo, M. Sarra, G. Sica, P. Sileri, L. Biancone, T.T. MacDonald, F. Pallone, G. Monteleone, Aryl hydrocarbon receptor-induced signals upregulate IL-22 production and inhibit inflammation in the gastrointestinal tract, Gastroenterology 141 (2011) 237-248.

[32] K.T. Jeong, S.J. Hwang, G.S. Oh, J.H. Park, FICZ, a tryptophan photoproduct, suppresses pulmonary eosinophilia and Th2-type cytokine production in a mouse model of ovalbumin-induced allergic asthma, Int. Immunopharmacol. 13 (2012) 377-385.

[33] N. Novac, W.M. Peng, T. Bieber, C. Akdis, FceRI stimulation promotes the differentiation of histamine receptor 1 -expressing inflammatory macrophages, Allergy 68 (2013) 454-461.

[34] M. Böhme, C. Söderhäll, I. Kull, A. Bergström, M. van Hage, C.F. Wahlgren, Filaggrin mutations increase the risk for persistent dry skin and eczema independent of sensitization, J. Allergy Clin. Immunol. 129 (2012) 1153-1155

[35] T. Czarnowicki, H. Esaki, J. Gonzalez, D. Malajian, A. Shemer, S. Noda, S. Talasila, A. Berry, J. Gray, L. Becker, Y. Estrada, H. Xu, X. Zheng, M. Suárez-Fariñas, J.G. Krueger, A.S. Paller, E. Guttman-Yassky, Early pediatric atopic dermatitis shows only a cutaneous lymphocyte antigen $(\mathrm{CLA})(+) \mathrm{TH} 2 / \mathrm{TH} 1$ cell imbalance, whereas adults acquire CLA(+) TH22/TC22 cell subsets, J. Allergy Clin. Immunol. 136 (2015) 941-951.
[36] H. Esaki, P.M. Brunner, Y. Renert-Yuval, T. Czarnowicki, T. Huynh, G. Tran, S. Lyon, G. Rodriguez, S. Immaneni, D.B. Johnson, B. Bauer, J. Fuentes-Duculan, X Zheng, X. Peng, Y.D. Estrada, H. Xu, C. de Guzman Strong, M. Suárez-Fariñas, J.G. Krueger, A.S. Paller, E. Guttman-Yassky, Early-onset pediatric atopic dermatitis is TH2 but also TH17 polarized in skin, J. Allergy Clin. Immunol. 138 (2016) 1639-1651.

[37] E. Guttman-Yassky, B. Ungar, K. Malik, D. Dickstein, M. Suprun, Y.D. Estrada, H. Xu, X. Peng, M. Oliva, D. Todd, T. Labuda, M. Suarez-Farinas, R. Bissonnette, Molecular signatures order the potency of topically applied anti-inflammatory drugs in patients with atopic dermatitis, Clin. Immunol. (2018), doi:http://dx. doi.org/10.1016/j.jaci.2017.01.027.

[38] H. Lou, J. Lu, E.B. Choi, M.H. Oh, M. Jeong, S. Barmettler, Z. Zhu, T. Zheng, Expression of IL-22 in the skin causes Th2-biased Immunity epidermal barrier dysfunction, and pruritus via stimulating epithelial Th2 cytokines and the GRP pathway, J. Immunol. 198 (2017) 2543-2555.

[39] D. Gutowska-Owsiak, A.L. Schaupp, M. Salimi, S. Taylor, G.S. Ogg, Interleukin22 downregulates filaggrin expression and affects expression of profilaggrin processing enzymes, Br. J. Dermatol. 165 (2011) 492-498.

[40] K.E. Nograles, L.C. Zaba, A. Shemer, J. Fuentes-Duculan, I. Cardinale, T. Kikuchi, M. Ramon, R. Bergman, J.G. Krueger, E. Guttman-Yassky, IL-22-producing T22 T cells account for upregulated IL-22 in atopic dermatitis despite reduced IL-17producing TH17 T cells, J. Allergy Clin. Immunol. 123 (2009) 1244-1252.

[41] J. Qiu, L. Zhou, Aryl hydrocarbon receptor promotes ROR $\gamma \mathrm{t}^{+}$group 3 ILCs and controls intestinal immunity and inflammation, Semin. Immunopathol. 35 (2013) 657-670.

[42] J.H. Duarte, P. Di Meglio, K. Hirota, H. Ahlfors, B. Stockinger, Differential influences of the aryl hydrocarbon receptor on Th17 mediated responses in vitro and in vivo, PLoS One 8 (2013) e79819.

[43] A. Wollenberg, A. Oranje, M. Deleuran, D. Simon, Z. Szalai, B. Kunz, A. Svensson, S. Barbarot, L. von Kobyletzki, A. Taieb, M. de Bruin-Weller, T. Werfel, M. Trzeciak, C. Vestergard, J. Ring, U. Darsow, European Task Force on Atopic Dermatitis/EADV Eczema Task Force, ETFAD/EADV Eczema task force 2015 position paper on diagnosis and treatment of atopic dermatitis in adult and paediatric patients, J. Eur. Acad. Dermatol. Venereol. 30 (2016) 729-747.

[44] H. Saeki, T. Nakahara, A. Tanaka, K. Kabashima, M. Sugaya, H. Murota, T. Ebihara, Y. Kataoka, M. Aihara, T. Etoh, N. Katoh, Committee for Clinical Practice Guidelines for the Management of Atopic Dermatitis of Japanese Dermatological Association, Clinical practice guidelines for the management of atopic dermatitis 2016, J. Dermatol. 43 (2016) 1117-1145.

[45] F. Almutawa, N. Alnomair, Y. Wang, I. Hamzavi, H.W. Lim, Systematic review of UV-based therapy for psoriasis, Am. J. Clin. Dermatol. 14 (2013) 87-109.

[46] T. Schwarz, The dark and the sunny sides of UVR-induced immunosuppression: photoimmunology revisited, J. Invest. Dermatol. 130 (2010) 49-54.

[47] F. Navid, A. Bruhs, W. Schuller, E. Fritsche, J. Krutmann, T. Schwarz, A. Schwarz, The Aryl hydrocarbon receptor is involved in UVR-induced immunosuppression, J. Invest. Dermatol. 133 (2013) 2763-2770.

[48] S.P. Hong, M.J. Kim, M.Y. Jung, H. Jeon, J. Goo, S.K. Ahn, S.H. Lee, P.M. Elias, E.H. Choi, Biopositive effects of low-dose UVB on epidermis: coordinate upregulation of antimicrobial peptides and permeability barrier reinforcement, J. Invest. Dermatol. 128 (2008) 2880-2887. 